\title{
Has Creativity Research Become a Trivial Pursuit?
}

Todd Lubart

Université Paris Descartes, France

E-mail address: todd.lubart@parisdescartes.fr

\author{
Xavier Caroff \\ Université Paris Descartes, France \\ E-mail address: xavier.caroff@parisdescartes.fr
}

ARTICLE INFO

\section{Keywords:}

Creativity measurement

EPoC

Divergent thinking

Psychometric approach

\section{Article history:}

Received 30 November 2014

Received in revised form 21 December 2014

Accepted 22 December 2014

ISSN: 2354-0036

DOI: $10.1515 /$ ctra-2015-0006
A B STRACT

Based on Glăveanu's target article, issues raised about the psychometric approach to creativity research are examined. Criticisms of divergent thinking tests, such as the unusual uses of an object test, are examined. Arguments supporting the theoretical and practical utility of divergent thinking tests are presented. It is furthermore suggested that tests are best conceived and used in contextualized ways. The example of measures of divergent thinking which were designed for managers is presented. Finally, the psychometric approach encompasses many aspects of creativity beyond divergent thinking, as illustrated by recent work on the evaluation of creative potential (the EPoC battery). In the EPoC assessment, both divergent-exploratory thinking and convergent-integrative thinking are measured in a range of contextual domains, such as the visual-graphic, verballiterary, social problem solving ones. This work contrasts with the simplistic, and restrictive view of the unusual uses of an object test as the epitome of the psychometric approach to creativity.

In his thought-provoking article, Vlad Glăveanu raises a number of questions about creativity research ranging from the validity of the basic assumptions underlying the bedrock on which much research has been designed, to the ultimate take-home message in practical terms, of all the work. Indeed, it is useful to ask if the research community is on the right track. However, is there a right track - or many right tracks which are each somewhat worthy, and somewhat unworthy of investigation? Ultimately, the target article suggests that creativity research may be undergoing an existential crisis - or at least one creativity researcher is (namely Vlad Glăveanu). Is this an isolated case or are we at the beginning of an epidemic that will soon spread throughout the field?

The target article argues for a situated, contextualized approach to creativity research. This approach is particularly centered on cultural and action-based theory. The preferred methodology is qualitative investigation. It is suggested that alternative approaches to re- 
search - notably the quantitative, experimental or psychometric ones which have dominated the literature since the 1950s - have paid so much attention to the tree (or the branch of the tree, or even the leaves) that the forest has disappeared. In a word, if the essential reason for studying the tree is to better understand the forest (the big picture), we may have lost sight of the objective in the process. Glăveanu writes: the quantification of creativity goes hand in hand with its simplification to the point of not recognising anymore the phenomenon that we are trying so hard to understand (p. 21). If this is true, creativity research has become a trivial pursuit.

To address this issue, we will examine divergent thinking tests, and in particular take the unusual uses test as a case study. On this point, Glăveanu writes: "The whole edifice of psychometric creativity testing, following Guilford's (1950) foundational input, is mainly built around divergent thinking tasks and this long tradition is not about to change any time soon. And this despite repeated calls for expanding such a narrow view and increasing the ecological validity of our approach" (...) "How (...) [is the] experiential and ontological richness of creativity as a phenomenon ever contained in a task like "please generate as many uses as possible for a brick'? (p.16)" .

This citation merits several remarks. The tradition of divergent thinking measures of creativity can be traced far back to early work on chains of associations underlying creative thought. Often cited in introspective reports, this kind of associative play led to some early divergent thinking tests, starting in the late 19th century. The often-cited 1950 APA presidential address of Joy P. Guilford represented a big bang for divergent thinking tests. The field of creativity research started to grow rapidly, and divergent thinking ability became one of the main topics. Work with children led to the Wallach and Kogan creativity tests (WKCT) and the Torrance Tests of Creative Thinking (TTCT) to cite the most known. Work with adults, popularized by Alex Osborn's book on brainstorming led to a long line of work and the development of Creative Problem Solving (CPS) in organizational settings, based on divergent thinking, to a large extent, in line with Guilford's approach.

However, it became clear that all creativity tests cannot be reduced to divergent thinking, and even within divergent thinking tests there is diversity. This focus on one tree or one species of trees in the larger forest has historically reduced work on other facets of creativity, within creative cognition, and more generally in creativity. Each choice has its consequences and choosing to focus a certain amount of research on divergent thinking came with the opportunity cost of other topics being less studied. However, researchers who focused on divergent thinking, in particular, using the psychometric approach, in general, were not necessarily barking up the wrong tree. 
Indeed, when considering divergent thinking tests it is pertinent to distinguish two levels of analysis. One concerns, from a theoretical point of view, the concept of divergent thinking and its interest for fundamental research on creativity; the other concerns the tasks developed to measure this divergent thinking ability.

At the theoretical level first, since Guilford's (1950) pioneering work we postulate that creative people have a capacity for divergent thinking that traditional tests of intelligence do not measure. However, some authors have raised doubts about the distinctiveness of divergent thinking and intelligence, or the prediction of creative performance based on divergent thinking tests compared to intelligence tests. Kim's (2008) metaanalysis shows that creative performance is significantly more correlated with divergent thinking than traditional intelligence, even if these correlations are modest and show some heterogeneity. The correlations vary based on the type of divergent thinking test used and the type of measure of creative performance or achievement.

Concerning a critical analysis of "divergent thinking" tasks themselves, tests of unusual uses of a common object, such as a brick or a cardboard box, have been widely used and the question of their legitimate interest as a creativity measure has naturally been raised. If university students can think of more or less original uses for a brick, and we can relate this to some personality traits, or brain activity correlates, should we get excited? Some suggest that these kinds of measures have low face validity, and seem so far removed from eminent cases, such as Einstein, that studies using these measures are irrelevant and devoid of meaning. The psychometric approach is equated with these tests, and the story ends there.

We admit readily that unusual uses of an object can appear to be relatively rudimentary and not very "useful" for evaluating creative capacity in many domains. However, the task can be adapted to the constraints of the situation or the research objectives. A study conducted by Scratchley and Hakstian (2001) illustrates this approach in work on detecting creative potential in managers during a recruitment procedure. They defined managerial creativity as the capacity of a manager to produce new concepts, ideas, orientations, procedures and which would be useful in business. They hypothesized that divergent thinking would contribute to idea generation performance. However, they anticipated Vlad Glăveanu's remark. To avoid asking managers to generate unusual uses of a brick, they developed three content-relevant tasks to measure divergent thinking related to management; one was brainstorming solutions for a typical management problem, a second required noting the maximum number of similarities between two objects, and the third was a remote association task. Their results show the validity of these tasks 
within the selection procedure. A limit of this study was the lack of analysis of managers' activities in order to understand exactly the nature of creative managerial activity and the specific competencies that are involved. However, to go beyond the methodological limits of the unusual uses of an object test, it is best to develop specific measures of divergent thinking after first identifying the specifics of how this ability is involved in the creative activity that is under study. In order to proceed in this manner, it is possible to use traditional techniques of activity analysis, adapting them as needed to the research context (Caroff \& Lubart, 2012).

In our recent work with the measurement of creative potential in children and adolescents, we have developed a related, contextualized approach. In the EPoC battery (Evaluation of Potential Creativity: Lubart, Besançon \& Barbot, 2011), creative potential is conceived as a complex pattern that involves divergent-exploratory thinking and convergent-integrative thinking. These thinking processes are expressed in a content domain, such as visual-artistic, verbal-literary, social, scientific or musical sectors of activity. In each case, when divergent thinking is involved, it is not isolated from other components, including other cognitive abilities, personality and motivational tendencies. For example, divergent thinking ability involves knowledge, search mechanisms, personality traits such as openness and perseverance, as well as motivational and emotional factors. In addition to the divergent-exploratory mode, there is equal emphasis on the convergentintegrative mode of thinking. Each EPoC task engages the creative process in a substantiated content domain; for example, in the verbal domain the tasks involve providing several endings to a story in the divergent-exploratory measures, and inventing a complete story that integrates several elements in the convergent-integrative measures. Thus, the reality of psychometric assessments is again more complex than the unusual uses of an object test which epitomizes the psychometric approach for many people.

In summary, it is useful to note that in research, as in practical settings, the psychometric approach to creativity cannot be reduced simply to divergent thinking tests. Albeit that divergent thinking may well be one of the fundamental «bricks » for future work on creativity, in the multivariate conception (Lubart et al., 2003; Sternberg \& Lubart, 1995) creativity stems from a wide range of psychological characteristics (cognitive, conative and emotional) which can be assessed with a range of different tools, including questionnaires and tests. Discriminant, reliable, and valid measures - psychometrically sound ones - are needed ultimately to advance knowledge on creativity and answer the questions that are worth asking. 


\section{REFERENCES}

Caroff, X., \& Lubart, T. (2012). Multidimensional Approach to Detecting Creative Potential in Managers. Creativity Research Journal, 24, 1, 13-20; DOI: 10.1080/10400419. 2012.652927.

Glăveanu, V. P. (2014). The psychology of creativity: A critical reading. Creativity. Theories - Research - Applications, 1, 10-32; DOI: 10.15290/ctra.2014.01.01.02.

Guilford, J. P. (1950). Creativity. American Psychologist, 5, 444-454.

Kim, K. H. (2008). Meta-Analyses of the Relationship of Creative Achievement to Both IQ and Divergent Thinking Test Scores. The Journal of Creative Behavior, 42, 2, 106130; DOI:10.1002/j.2162-6057.2008.tb01290.x.

Lubart, T., Besançon, M., \& Barbot, B. (2011). EPoC: Evaluation du potentiel créatif [Evaluation of potential creativity]. Paris : Hogrefe.

Lubart, T. , Mouchiroud, C., Tordjman, S., \& Zenasni, F. (2003). Psychologie de creativité [Psychology of creativity]. Paris: Armand Colin.

Scratchley, L. S., \& Hakstian, A. R. (2001). The measurement and prediction of managerial creativity. Creativity Research Journal, 13, 3-4, 367-384; DOI:10.1207/ S15326934CRJ1334.

Sternberg, R.J. \& Lubart, T. (1995). Defying the crowd. New York: Free Press.

Corresponding author at: Todd Lubart \& Xavier Caroff, Laboratoire Adaptations Travail Individu (EA4469), Université Paris Descartes, Paris Cité Sorbonne, 71 Avenue Edouard Vaillant, 92100 Boulogne-Billancourt, France

E-mail: todd.lubart@parisdescartes.fr

E-mail: xavier.caroff@parisdescartes.fr 